\title{
Overweight and weight dissatisfaction related to socio- economic position, integration and dietary indicators among South Asian immigrants in Oslo
}

\author{
Marte Råberg ${ }^{1, *}$, Bernadette Kumar ${ }^{2}$, Gerd Holmboe-Ottesen ${ }^{2}$ and Margareta Wandel ${ }^{1}$ \\ 'Department of Nutrition, Institute for Basic Medical Sciences, University of Oslo, PB 1046 Blindern, 0316 Oslo, \\ Norway: ${ }^{2}$ Section for Preventive Medicine and Epidemiology, Institute of General Practice and Community \\ Medicine, University of Oslo, Oslo, Norway
}

Submitted 19 September 2008: Accepted 27 August 2009: First published online 7 0ctober 2009

\begin{abstract}
Objective: To investigate how socio-economic position, demographic factors, degree of integration and dietary indicators are related to BMI/waist:hip ratio (WHR) and to weight dissatisfaction and slimming among South Asians in Oslo, Norway.

Design: Cross-sectional study consisting of a health check including anthropometric measures and two self-administered questionnaires.

Setting: Oslo, Norway.

Subjects: Pakistanis and Sri Lankans ( $n$ 629), aged 30-60 years, residing in Oslo. Results: BMI was positively associated with female gender $(P=0 \cdot 004)$ and Pakistani origin $(P<0 \cdot 001)$, and inversely associated with years of education $(P=0 \cdot 011)$ and eating more hot meals $(P=0 \cdot 016)$. WHR was positively associated with male gender $(P<0 \cdot 001)$, age $(P<0 \cdot 001)$ and a dietary pattern with high-fat foods $(P=0 \cdot 005)$, and inversely associated with degree of integration (measured by a composite index, independent of duration of residence; $P=0 \cdot 017)$. One-third of those with normal weight and most of those obese were dissatisfied with their weight. Among these, about $40 \%$ had attempted to slim during the past year. Dissatisfaction with weight was positively associated with education in women $(P=0.006)$ and with integration in men $(P=0 \cdot 026)$, and inversely associated with physical activity $(P=0 \cdot 044)$ in men. Women who had made slimming attempts had breakfast and other meals less frequently than others $(P<0 \cdot 05)$.

Conclusions: Weight dissatisfaction exists among South Asian immigrants. More research is needed regarding bodily dissatisfaction and the relationship between perception of weight and weight-change attempts among immigrants in Norway, in order to prevent and treat both obesity and eating disorders.
\end{abstract}

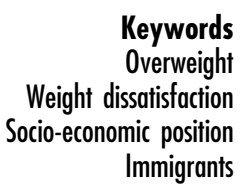

Keywords issatisfaction Immigrants
The obesity epidemic has become a worldwide problem $^{(1)}$. Repeated studies have shown that obesity and related diseases, such as type 2 diabetes and CHD, may be more prevalent among non-Western immigrants than among the host population in Western countries ${ }^{(2-6)}$. Earlier research indicates that migrating from a less to a more industrialized country may lead to weight increase, which is often positively related to the length of stay in the new country ${ }^{(7-9)}$.

Integration and acculturation processes, together with psychological strain related to migration, affect lifestyle, including diet and physical activity ${ }^{(10,11)}$. Notions of ideal body shape vary from culture to culture ${ }^{(12)}$ and are also likely to change in the new environment. The Western ideal for women is to be thin, whereas a more generous shape has traditionally been preferred e.g. on the Indian subcontinent ${ }^{(13)}$. Bodily dissatisfaction and related disordered eating have previously been viewed as problems existing mainly among white women. However, several studies show that Asian women in the USA are more dissatisfied with their bodies and engage in weight-loss behaviour to a larger extent than white women ${ }^{(14)}$. This may be a consequence of exposure to the thin ideal ${ }^{(15)}$, possibly together with weight increase. The relationship between weight dissatisfaction and weight-related behaviour is not necessarily the same in all cultures. A study comparing first-generation South Asian and Italian women and the general female population in Great Britain showed that the South Asian immigrants were most dissatisfied with their weight, but had less often than 
the others felt any pressure or tried to lose weight ${ }^{(16)}$. A review of studies of weight perceptions among men ${ }^{(17)}$ found it was more common among non-white men to consider a higher body weight as desirable than among white men, and fewer classified themselves as overweight.

Which aspects of the integration process and which other factors in the immigrants' lives are connected to weight status, have not been studied in detail. Such knowledge is of great importance in the work to reduce the prevalence of overweight/obesity and related chronic diseases in the immigrant population ${ }^{(18,19)}$.

People from South Asia constitute the largest nonWestern immigrant group in Norway. Most of them come from Pakistan and Sri Lanka. They are among the immigrants with longest duration of residence in the country ${ }^{(20)}$. They are also among those with the highest risk of developing obesity and type 2 diabetes $^{(21)}$. The present study aimed to investigate:

1. The relationship between $\mathrm{BMI} /$ waist:hip ratio (WHR) among South Asian immigrants and length of stay in Norway, socio-economic position and degree of integration, as well as the relationship to meal patterns and intake frequency of certain foods, high in fat and sugar.

2. South Asian immigrants' perception of own body weight, the extent to which dissatisfaction results in slimming, and if dissatisfaction and slimming are related to socio-economic position, integration and certain dietary patterns.

\section{Methods}

\section{Design}

The Oslo Immigrant Health Study (Immigrant-HUBRO) was conducted by the Norwegian Institute of Public Health and the University of Oslo in 2002. Oslo residents, born in Pakistan, Sri Lanka, Iran, Turkey and Vietnam, were invited to attend. This study followed after the Oslo Health Study (HUBRO). Both used the same protocol and are described elsewhere (http://www.fhi.no/hubro). The study was performed according to the Helsinki Declaration. The Norwegian Data Inspectorate approved the study and it was cleared by the Regional Committee for Medical Research Ethics.

The study consisted of a health check including anthropometric measures and two self-administered questionnaires. A letter of invitation to health screening, a consent form and the main questionnaire were sent to all invited persons. A reminder was sent to non-responders of the first invitation. Information about the study was also given through special immigrant television programmes, newspaper articles and visits made by the study coordinators to mosques and immigrant organizations. Assistance in a preferred language (Norwegian, English, Urdu, Punjabi or Tamil) was offered at the screening stations. Upon arrival, an additional questionnaire was distributed.

\section{Sample}

The participants were 30-60 years old, born in Pakistan or Sri Lanka, and living in Oslo. Of 3738 persons invited, 3384 were reached by mail. Out of these, 1501 persons answered the main questionnaire, giving a response rate of $44 \%$ (31.7\% for Pakistanis and $50 \cdot 9 \%$ for Sri Lankans). The final number of participants included those who had answered the additional questionnaire, which was 629 (218 Pakistanis, 411 Sri Lankans). An earlier comparison between the participants in Immigrant-HUBRO who answered one or both questionnaires showed only small differences with regard to age, gender, nationality, education and work ${ }^{(22)}$.

\section{Measures}

The main questionnaire contained questions about health, self-reported disease, sociodemographic factors and some food frequency questions. The food frequency questions were the same as previously used in the Oslo Health Study 2000-2001 for Norwegians, and included intake of fruit, vegetables, cheese and fish with the response categories of 'seldom/never', '1-3 times/month', '1-3 times/week', '4-6 times/week', ' $1-2$ times/d' and ' $\geq 3$ times/d', as well as intake of milk, juice and soft drinks with the response categories of 'seldom/never', '1-6 glasses/week', ' 1 glass/d', '2-3 glasses/d' and ' $\geq 4$ glasses/d'. The additional questionnaire included questions related to life conditions as immigrants and more detailed food frequency questions. The food frequency questions were validated previously for ethnic Norwegians ${ }^{(23)}$ and revised after a pilot study with 130 Pakistanis to make the questions suitable for this population. Out of the sixtyseven food and drink items, forty-three were retained, twelve were dropped and twelve items were either new or had been reworded. It included intake of different breads (number of slices/d), bread spreads ('seldom/ never', '1-2 times/week', '3-4 times/week', '5-7 times/ week' and 'several times/d'), dinner dishes, dressings etc., cakes/sweets/snacks and fats ('seldom/never', '1-3 times/ month', '1-2 times/week', '3-4 times/week' and '5-7 times/ week').

South Asians traditionally eat several hot meals a day, but the number of hot meals often declines after migration to a Western country ${ }^{(22)}$. The numbers of meals (hot and total) the participants reported to eat per day were analysed as continuous variables, but were recoded into dichotomous variables for logistic regression: meals in total, $0=\leq 2$ and $1=\geq 3$; and hot meals, $0=\leq 1$ and $1=\geq 2$. Frequency of consumption of the different meals (breakfast, lunch, dinner, evening meal and snack) was coded as $0=\leq 4$ times/week and $1=\geq 5-6$ times/week.

Previous analyses of the same sample revealed that those who reported to eat mainly Norwegian dishes also ate fish, sausages, burgers and spaghetti/macaroni more frequently than others ${ }^{(22)}$. On this basis we made an index for a Norwegian eating pattern, including these 
four items. Each item could contribute with 0-4 points depending on intake frequency and the total score for the index ranged from 0 to 16 . For the logistic regression the total score was coded as 0 for the $70 \%$ with the lowest intake frequency and as 1 for the $30 \%$ with the highest frequency.

The results from a previous $24 \mathrm{~h}$ recall study among Pakistani women were used to identify the food items that contributed substantially to fat and sugar intake ${ }^{(24)}$. Based on this, we made two indices as measures of diets rich in fat and sugar. The food groups contributing most to dietary fat were cooking fat, meat and meat products, milk and milk products, snacks and fatty desserts/biscuits/ cakes. Weekly frequency of intake was divided into three categories $($ high $=3$, medium $=2$ or low $=1$ ) and then added to compute a total score (variation of score: 5-15). For the logistic regression the $30 \%$ with the highest score was coded as 1 , the others as 0 . The same procedure was followed for the score on sugar-rich foods, which were sugar added to foods and drinks, sugar-sweetened soft drinks and nectars, and sweet desserts/jam/cakes/cookies (variation of score: 3-9).

BMI and WHR were calculated from the anthropometric measures taken at the screening and analysed as continuous variables. BMI was also recoded into groups: underweight $\left(\mathrm{BMI}<18 \cdot 5 \mathrm{~kg} / \mathrm{m}^{2}\right)$, normal weight $(\mathrm{BMI}=$ $\left.18 \cdot 5-24.9 \mathrm{~kg} / \mathrm{m}^{2}\right)$, overweight $\left(\mathrm{BMI}=25 \cdot 0-29 \cdot 9 \mathrm{~kg} / \mathrm{m}^{2}\right)$ and obesity $\left(\mathrm{BMI} \geq 30 \cdot 0 \mathrm{~kg} / \mathrm{m}^{2}\right)$. The participants were asked whether they were satisfied with their weight or not, and if not, which weight they wished to have. The difference between this and measured weight indicated if the participants desired to weigh less or more. From desired weight and measured height, we calculated desired BMI. For those satisfied with their weight, actual BMI was used as desired BMI. We also asked if they had attempted to slim during the past year, regardless of weight dissatisfaction. A dichotomized variable with a specific cut-off (BMI $\geq 27 \cdot 5 \mathrm{~kg} / \mathrm{m}^{2}$ ) for Asians, indicating high risk of chronic diseases, was used as suggested by the WHO expert consultation group ${ }^{(25)}$; the values were set to $0\left(\mathrm{BMI}<27 \cdot 5 \mathrm{~kg} / \mathrm{m}^{2}\right)$ and $1\left(\mathrm{BMI} \geq 27 \cdot 5 \mathrm{~kg} / \mathrm{m}^{2}\right)$.

Age, number of children, years in Norway and years of education were analysed as continuous variables. 'Years of education' included education from both Norway and the country of origin. As current occupation may not correspond to educational level or employment in the country of origin, we chose to use the variable 'being in income-generating work or not' as an indicator of working situation. This was recoded to a dichotomous variable: $1=$ have income-generating work (any), $0=$ no income-generating work. Smoking status was assessed with three response categories, and recoded as follows: $1=$ yes, now (current smoker), $0=$ never or previous smoker. Self-reported leisure-time physical activity was assessed with a four-graded measure, inactive to very active, and recoded to a dichotomous variable:
$0=$ sedentary activities (e.g. reading, watching television), $1=$ moderate physical activities (e.g. walking, cycling) or heavier activities for $\geq 4 \mathrm{~h} /$ week. Integration was assessed by an index computed from three questions regarding reading Norwegian newspapers, having Norwegians visiting one's home and participating in organizations in Norway. Each of the variables could contribute with $0-3$ points, which added up to a scale from 0 to 9.

Information about country of birth, age, gender and residential address was provided from the Norwegian Registry of Vital Statistics. Ethnicity was determined on the basis of country of birth. A cross-check with Statistics Norway's registers confirmed that in $99 \cdot 8 \%$ of cases the country of birth was identical to the self-reported 'country of origin'.

\section{Statistical analyses}

Data were analysed using the SPSS statistical software package version $14 \cdot 0$ (SPSS Inc., Chicago, IL, USA). Differences between groups were tested by cross tables and $\chi^{2}$ statistics. The associations between BMI/WHR and gender, age, years in Norway, nationality, number of children, socio-economic variables (education and incomegenerating work), integration, smoking and physical activity were tested by multiple linear regression models. We also added different diet-related variables one by one, to find possible associations with BMI/WHR. Only the dietrelated variables with significant associations with BMI/ WHR were added to the final model. Furthermore, we studied the associations between weight dissatisfaction/ slimming and age, nationality, socio-economic position, integration, physical activity and BMI using multiple logistic regression models, and also how being dissatisfied or having tried to lose weight influences eating behaviour. The analyses regarding weight dissatisfaction and slimming were done for men and women separately. The significance level was set to $P<0 \cdot 05$.

\section{Results}

\section{Characteristics of the sample}

The Sri Lankans were a little younger than the Pakistanis. The participants had been living in Norway between 1 and 34 years, the Pakistanis on average longer than the Sri Lankans (Table 1). Despite shorter time in Norway, the Sri Lankans scored somewhat higher on the index measuring integration $(P=0 \cdot 008)$. Sri Lankans also had longer education on average and a higher proportion in incomegenerating work. Overweight/obesity $\left(\mathrm{BMI} \geq 25 \cdot 0 \mathrm{~kg} / \mathrm{m}^{2}\right.$ ) was present in $58.2 \%$ of the Sri Lankans and $76.5 \%$ of the Pakistanis; between $22.5 \%$ and $54.9 \%$ had a high health risk $\left(\mathrm{BMI} \geq 27 \cdot 5 \mathrm{~kg} / \mathrm{m}^{2}\right.$ ). The proportion of obese (BMI $\geq 30 \cdot 0 \mathrm{~kg} / \mathrm{m}^{2}$ ) individuals varied from $5 \cdot 5 \%$ among Sri Lankan men to $31.9 \%$ among Pakistani women (Table 1). Mean WHR was 0.85 and 0.86 in women and 0.92 and 
Table 1 Characteristics of the study sample: Pakistani and Sri Lankan immigrants, aged 30-60 years, residing in Oslo, 2002

\begin{tabular}{|c|c|c|c|c|c|}
\hline & \multicolumn{2}{|c|}{ Sri Lanka } & \multicolumn{2}{|c|}{ Pakistan } & \multirow[b]{2}{*}{$P$ value* } \\
\hline & $\begin{array}{c}\text { Women } \\
(n \text { 175) }\end{array}$ & $\begin{array}{c}\text { Men } \\
(n \text { 236) }\end{array}$ & $\begin{array}{c}\text { Women } \\
(n 91)\end{array}$ & $\begin{array}{c}\text { Men } \\
(n 127)\end{array}$ & \\
\hline Age (years), mean & $40 \cdot 0$ & $40 \cdot 7$ & $44 \cdot 5$ & $44 \cdot 2$ & $<0.001$ \\
\hline Years in Norway, mean & $10 \cdot 8$ & $14 \cdot 3$ & $17 \cdot 9$ & $21 \cdot 9$ & $<0.001$ \\
\hline Education (years), mean & $12 \cdot 2$ & $13 \cdot 3$ & $8 \cdot 7$ & $11 \cdot 9$ & $<0.001$ \\
\hline Income-generating work (\%) & 63 & 85 & 27 & 73 & $<0.001$ \\
\hline Hot meals (number/d) & 1.6 & $1 \cdot 6$ & $1 \cdot 4$ & $1 \cdot 4$ & 0.015 \\
\hline Meals in total (number/d) & $3 \cdot 1$ & $3 \cdot 1$ & $2 \cdot 9$ & $2 \cdot 7$ & $<0.001$ \\
\hline Norwegian diet (proportion within 30\% with the highest intake) & 37 & 38 & 2 & 6 & $<0.001$ \\
\hline Foods high in fat (proportion within $30 \%$ with the highest intake) & 35 & 37 & 29 & 25 & 0.021 \\
\hline Foods high in sugar (proportion within $30 \%$ with the highest intake) & 34 & 36 & 23 & 31 & 0.052 \\
\hline WHR, mean & 0.85 & 0.92 & 0.86 & 0.94 & 0.002 \\
\hline BMI $\left(\mathrm{kg} / \mathrm{m}^{2}\right)$, mean & $26 \cdot 3$ & $25 \cdot 6$ & $28 \cdot 8$ & $27 \cdot 3$ & $<0.001$ \\
\hline Underweight, $\mathrm{BMI}<18.5 \mathrm{~kg} / \mathrm{m}^{2}(\%)$ & 0.6 & 0.8 & $1 \cdot 1$ & 0.8 & $1 \cdot 000$ \\
\hline Normal weight, $\mathrm{BMI}=18.5-24.9 \mathrm{~kg} / \mathrm{m}^{2}(\%)$ & $36 \cdot 6$ & $44 \cdot 5$ & $19 \cdot 8$ & $24 \cdot 6$ & $<0.001$ \\
\hline Overweight, $\mathrm{BMI}=25 \cdot 0-29 \cdot 9 \mathrm{~kg} / \mathrm{m}^{2}(\%)$ & $46 \cdot 3$ & $49 \cdot 2$ & $47 \cdot 3$ & $54 \cdot 0$ & 0.529 \\
\hline Obesity, $\mathrm{BMI} \geq 30.0 \mathrm{~kg} / \mathrm{m}^{2}(\%)$ & $16 \cdot 6$ & $5 \cdot 5$ & $31 \cdot 9$ & $20 \cdot 6$ & $<0.001$ \\
\hline High disease riskt, $\mathrm{BMI} \geq 27.5 \mathrm{~kg} / \mathrm{m}^{2}(\%)$ & $30 \cdot 9$ & $22 \cdot 5$ & $54 \cdot 9$ & $47 \cdot 6$ & $<0.001$ \\
\hline Desired BMI $\left(\mathrm{kg} / \mathrm{m}^{2}\right)$, mean & $24 \cdot 4$ & $24 \cdot 9$ & $25 \cdot 3$ & $25 \cdot 5$ & 0.001 \\
\hline
\end{tabular}

WHR, waist:hip ratio.

*Significance of the difference between nationalities.

tBMI cut-off indicating high risk of chronic diseases among South Asians, suggested by the WHO expert consultation group ${ }^{(25)}$.

Table 2 Crude and adjusted coefficients and 95\% confidence intervals for associations between BMI/WHR and demographic, socioeconomic and lifestyle variables from linear regression models: Pakistani and Sri Lankan immigrants, aged 30-60 years, residing in Oslo, 2002

\begin{tabular}{|c|c|c|c|c|c|c|}
\hline & $B$ crude & $95 \% \mathrm{Cl}$ & $P$ value & $B$ adjusted & $95 \% \mathrm{Cl}$ & $P$ value \\
\hline \multicolumn{7}{|l|}{ BMI } \\
\hline Age & 0.076 & $0.037,0.114$ & $<0.001$ & 0.046 & $-0.001,0.092$ & 0.053 \\
\hline Years in Norway & 0.059 & $0 \cdot 016,0 \cdot 102$ & 0.007 & -0.007 & $-0.650,0.051$ & $0 \cdot 813$ \\
\hline Gender (ref: men) & 1.031 & $0.419,1.644$ & 0.001 & $1 \cdot 446$ & $0 \cdot 461,2 \cdot 431$ & 0.004 \\
\hline Nationality (ref: Sri Lankan) & $2 \cdot 032$ & $1 \cdot 410,2 \cdot 654$ & $<0.001$ & $1 \cdot 742$ & $0.910,2.575$ & $<0.001$ \\
\hline Number of children & 0.315 & $0 \cdot 125,0 \cdot 504$ & 0.001 & $-0 \cdot 153$ & $-0.465,0.159$ & 0.335 \\
\hline Income-generating work (ref: no) & -0.982 & $-1.653,-0.311$ & 0.004 & -0.084 & $-0.863,0.696$ & 0.833 \\
\hline Education & $-0 \cdot 154$ & $-0.226,-0.082$ & $<0.001$ & $-0 \cdot 113$ & $-0.201,-0.026$ & $0 \cdot 011$ \\
\hline Integration & $-0 \cdot 149$ & $-0.315,0.018$ & 0.080 & 0.011 & $-0.191,0.212$ & 0.915 \\
\hline Physical activity (ref: less active) & -0.089 & $-0.724,0.545$ & $0 \cdot 782$ & 0.020 & $-0.626,0.667$ & 0.951 \\
\hline Smoking (ref: yes) & 0.066 & $-0 \cdot 854,0 \cdot 987$ & 0.888 & $0 \cdot 172$ & $-0 \cdot 832,1 \cdot 175$ & 0.737 \\
\hline Hot meals/d & -0.410 & $-0.827,0.007$ & 0.054 & -0.544 & $-0.987,-0.100$ & 0.016 \\
\hline \multicolumn{7}{|l|}{ WHR } \\
\hline Age & 0.004 & $0.003,0.004$ & $<0.001$ & 0.003 & $0.003,0.004$ & $<0.001$ \\
\hline Years in Norway & 0.003 & $0.002,0.003$ & $<0.001$ & 0.000 & $-0.001,0.001$ & 0.608 \\
\hline Gender (ref: men) & -0.073 & $-0.084,-0.062$ & $<0.001$ & -0.081 & $-0.097,-0.064$ & $<0.001$ \\
\hline Nationality (ref: Sri Lankan) & 0.020 & $0.007,0.032$ & 0.002 & 0.004 & $-0.009,0.018$ & 0.530 \\
\hline Number of children & -0.012 & $-0.016,-0.009$ & $<0.001$ & 0.001 & $-0.005,0.006$ & 0.788 \\
\hline Income-generating work (ref: no) & 0.010 & $-0.003,0.023$ & $0 \cdot 136$ & -0.004 & $-0.017,0.009$ & 0.514 \\
\hline Education & -0.001 & $-0.002,0.000$ & $0 \cdot 199$ & 0.000 & $-0.002,0.001$ & $0 \cdot 727$ \\
\hline Integration & 0.000 & $-0.003,0.003$ & 0.966 & -0.004 & $-0.008,-0.001$ & 0.017 \\
\hline Physical activity (ref: less active) & -0.005 & $-0.017,0.008$ & 0.466 & -0.006 & $-0.017,0.004$ & $0 \cdot 245$ \\
\hline Smoking (ref: yes) & 0.033 & $0.015,0.051$ & $<0.001$ & 0.007 & $-0.010,0.024$ & 0.398 \\
\hline Food rich in fat & 0.003 & $-0.010,0.016$ & 0.640 & 0.017 & $0.005,0.028$ & 0.005 \\
\hline
\end{tabular}

ref, referent category; WHR, waist:hip ratio.

Adjusted for all independent variables.

Adjusted $R^{2}=11 \%$ for BMI; adjusted $R^{2}=35 \%$ for WHR

0.94 in men from Sri Lanka and Pakistan, respectively. Sri Lankans had on average more daily hot meals and meals in total than Pakistanis, and a higher proportion of Sri Lankans were also within the $30 \%$ with the highest frequency of intake of foods indicating a Norwegian diet, as well as within the $30 \%$ with the highest intake frequency of foods high in fat.

\section{BMI/waist:bip ratio related to integration, socio- economic position and diet}

After adjustment for age and gender, there was no significant association between the number of years lived in Norway and BMI or WHR. In the multivariate analyses (Table 2), Pakistani origin $(P<0 \cdot 001)$ and female gender $(P=0 \cdot 004)$ were positively associated with BMI, whereas 
years of education $(P=0 \cdot 011)$ and number of hot meals $(P=0 \cdot 016)$ were inversely associated. Male gender $(P<$ $0 \cdot 001)$, age $(P<0 \cdot 001)$ and foods rich in fat $(P=0 \cdot 005)$ were positively associated with WHR, while degree of integration was inversely associated $(P=0 \cdot 017)$ with WHR. The multivariate models explained $11 \%$ of the variation in BMI and $35 \%$ of the variation in WHR. The regression analyses were also carried out separately for women and men and for Sri Lankans and Pakistanis, and the associations were in the same direction for both genders and both nationalities.

\section{Weight dissatisfaction and slimming}

Almost 30\% of the normal-weight men and women, about half of those overweight and most of those obese were dissatisfied with their weight (Fig. 1). A greater proportion of women than men were dissatisfied with their weight $(P=0 \cdot 002)$. Among those dissatisfied, $21 \%$ of men and $6 \%$ of women wanted to gain weight $(P<0 \cdot 001)$. Out of those with normal weight who wanted to change weight, about $70 \%$ of the men wanted to gain weight, while about $80 \%$ of the women desired a lower weight. Most overweight and all obese who were dissatisfied with their weight wanted to weigh less. Men wanted an average weight change of $-2 \mathrm{~kg}$ (range: $-9 \mathrm{~kg}$ to $+19 \mathrm{~kg}$ ), while the respective amount for women was $-5 \mathrm{~kg}$ (range: $-21 \mathrm{~kg}$ to $+5 \mathrm{~kg}$ ). Mean desired BMI was within the normal-weight range among the Sri Lankans, but slightly above the cut-off point for overweight among the Pakistanis (Table 1). It was lower than mean actual BMI in both groups $(P<0 \cdot 001)$. Desired BMI increased with actual BMI $(P<0 \cdot 001)$ and for Sri Lankans it was positively associated with age $(P<0.001$ for women and $P=0.014$ for men; data not shown). Degree of integration or socio-economic position had no impact on desired BMI, except for Sri Lankan women among whom education was inversely associated with desired BMI $(P<0 \cdot 001)$.

Figure 1 also shows the proportion who had tried to slim in each weight group. A considerably greater proportion had attempted to slim during the past year among those who were dissatisfied with their weight, than among those who were satisfied ( $40 \% v .15 \% ; P<0 \cdot 001)$. Of those who wanted to weigh less, $49 \%$ of women and $39 \%$ of men had tried to slim during the past year. Almost all those of normal weight who wanted to weigh less had attempted to slim, whereas the wish for weight reduction corresponded less to slimming among the overweight and obese men and women. The proportion who had attempted to slim was not significantly different between Pakistanis and Sri Lankans (29\% v. 26\%), but there were more women in both groups ( $P=0 \cdot 001$; data not shown).

Weight dissatisfaction was increasing with BMI in both genders $(P<0 \cdot 001$ for both; Table 3$)$. Among women dissatisfaction was positively associated with education $(P=0 \cdot 006)$; among men it was inversely associated with

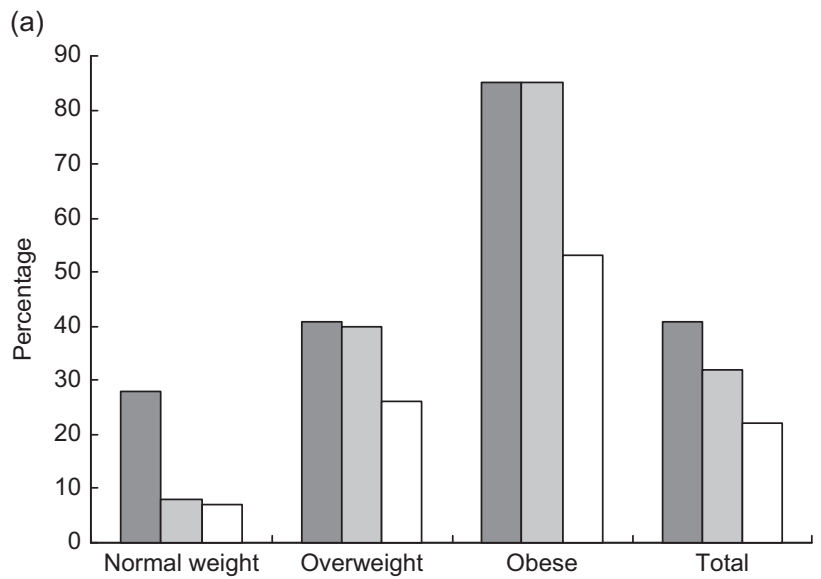

(b)

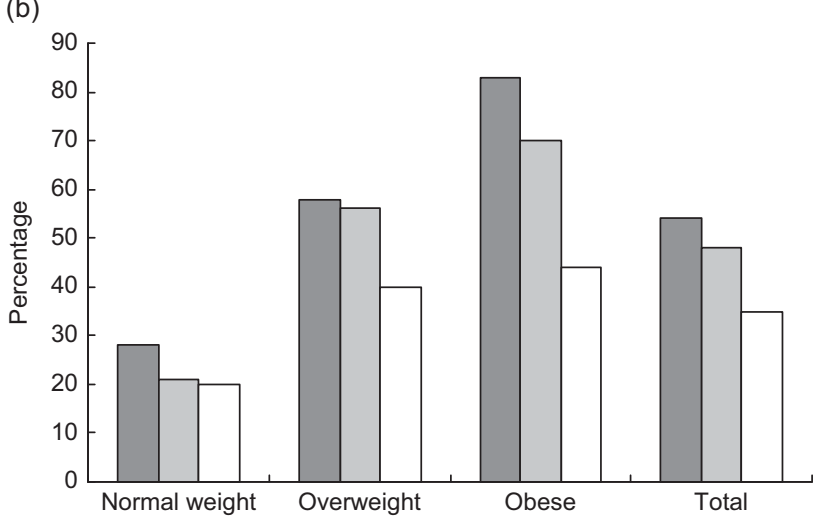

Fig. 1 Percentage dissatisfied with their weight $(\square)$, wanting to weigh less $(\square)$ and attempting to slim during the past year $(\square)$ in each BMI group among Pakistani and Sri Lankan immigrants, aged 30-60 years, residing in Oslo, 2002: (a) men ( $n$ 359; normal weight, $n$ 136; overweight, $n$ 184; obese, $n$ 39) and (b) women ( $n$ 264; normal weight, $n$ 82; overweight, $n$ 124; obese, $n$ 58). Underweight persons (three men, two women) were excluded

age $(P=0 \cdot 021)$, years lived in Norway $(P=0 \cdot 043)$ and physical activity $(P=0 \cdot 044)$, and positively associated with Pakistani origin $(P<0 \cdot 001)$ and integration $(P=0 \cdot 026)$. Slimming was positively associated with BMI in both genders ( $P=0.02$ for women, $P<0.001$ for men), and among men it was inversely associated with age $(P=0 \cdot 037)$ and income-generating work $(P=0 \cdot 013$; Table 3).

Results from logistic regression analyses showed that, for women, weight dissatisfaction and slimming were inversely associated with number of daily hot meals and number of meals in total $(P<0.05$; data not shown). Women who were slimming had breakfast less frequently than the other women $(P=0 \cdot 039)$. For men, being dissatisfied with weight was inversely related to the intake frequency of food items associated with a more Norwegian diet $(P=0 \cdot 003)$. There were no significant associations between slimming attempts and dietary indicators among men. 
Table 3 Odds ratios and $95 \%$ confidence intervals for weight dissatisfaction and slimming attempts related to demographic and socioeconomic factors, integration and lifestyle from logistic regression models: Pakistani and Sri Lankan immigrants, aged 30-60 years, residing in Oslo, 2002

\begin{tabular}{|c|c|c|c|c|c|c|}
\hline & \multicolumn{3}{|c|}{ Women } & \multicolumn{3}{|c|}{ Men } \\
\hline & OR & $95 \% \mathrm{Cl}$ & $P$ value & OR & $95 \% \mathrm{Cl}$ & $P$ value \\
\hline \multicolumn{7}{|l|}{ Weight dissatisfaction } \\
\hline Age & 0.987 & $0.942,1.033$ & 0.568 & 0.954 & $0.915,0.995$ & 0.021 \\
\hline Years in Norway & $1 \cdot 020$ & $0 \cdot 960,1 \cdot 084$ & 0.529 & 0.950 & $0.905,0.998$ & 0.043 \\
\hline Nationality (ref: Sri Lankan) & $2 \cdot 133$ & $0 \cdot 849,5 \cdot 357$ & $0 \cdot 107$ & $5 \cdot 487$ & $2 \cdot 680,11 \cdot 234$ & $<0.001$ \\
\hline Income-generating work (ref: no) & 0.520 & $0.520,1.061$ & 0.072 & 0.535 & $0 \cdot 262,1 \cdot 094$ & 0.086 \\
\hline Education & $1 \cdot 139$ & $1 \cdot 039,1 \cdot 250$ & 0.006 & $1 \cdot 048$ & $0 \cdot 978,1 \cdot 123$ & 0.294 \\
\hline Integration & 0.990 & $0 \cdot 800,1 \cdot 224$ & 0.923 & $1 \cdot 202$ & $1 \cdot 022,1 \cdot 414$ & 0.026 \\
\hline Physical activity (ref: less active) & $0 \cdot 680$ & $0 \cdot 360,1 \cdot 281$ & 0.233 & 0.583 & $0 \cdot 344,0.986$ & 0.044 \\
\hline BMI & $1 \cdot 310$ & $1 \cdot 183,1 \cdot 450$ & $<0.001$ & $1 \cdot 184$ & $1 \cdot 088,1 \cdot 288$ & $<0.001$ \\
\hline \multicolumn{7}{|l|}{ Slimming attempts during past year } \\
\hline Age & 0.974 & $0.932,1.018$ & 0.242 & 0.946 & $0.898,0.997$ & 0.037 \\
\hline Years in Norway & $1 \cdot 028$ & $0.970,1.089$ & 0.355 & $1 \cdot 045$ & $0 \cdot 986,1 \cdot 107$ & $0 \cdot 139$ \\
\hline Nationality (ref: Sri Lankan) & $0 \cdot 706$ & $0 \cdot 299,1 \cdot 666$ & 0.427 & $0 \cdot 847$ & $0 \cdot 378,1 \cdot 900$ & 0.687 \\
\hline Income-generating work (ref: no) & $0 \cdot 840$ & $0.421,1.678$ & 0.622 & $0 \cdot 360$ & $0 \cdot 160,0 \cdot 807$ & 0.013 \\
\hline Education & 0.985 & $0.905,1.073$ & 0.729 & $1 \cdot 019$ & $0 \cdot 934,1 \cdot 112$ & 0.671 \\
\hline Integration & $1 \cdot 206$ & $0 \cdot 978,1 \cdot 488$ & 0.079 & $1 \cdot 124$ & $0.928,1.361$ & 0.232 \\
\hline Physical activity (ref: less active) & $1 \cdot 012$ & $0.543,1.888$ & 0.969 & $1 \cdot 092$ & $0.573,2.081$ & 0.790 \\
\hline BMI & $1 \cdot 120$ & $1 \cdot 041,1 \cdot 205$ & 0.002 & $1 \cdot 328$ & $1 \cdot 194,1 \cdot 477$ & $<0.001$ \\
\hline
\end{tabular}

ref, referent category

Adjusted for all independent variables.

\section{Discussion}

\section{Metbod}

Immigrant groups from developing countries are very often excluded from national health studies due to low attendance and language problems. Several means, like the use of mass media, reminders and language support, were employed to enhance the participation rate in ImmigrantHUBRO. Even though the attendance rate achieved for South Asians was similar to that of ethnic Norwegians in HUBRO ( $44 \% v .46 \%$ ), this is still a low attendance rate, which may influence the results. Søgaard et al. analysed the non-responders of HUBRO and found that attendance was associated with age, education, income and female gender, both for ethnic Norwegians and non-Western immigrants ${ }^{(26)}$. However, the differences were rather small, and they concluded that the results were robust even in light of considerable non-attendance. It is likely that this is also true for Immigrant-HUBRO. The socio-economic profile, i.e. number of years in Norway, level of education and proportion in income-generating work, of the two ethnic groups in the sample was in agreement with data from Statistics Norway ${ }^{(20,27)}$. This suggests that the findings may be useful in planning interventions among Pakistani and Sri Lankan immigrants in Norway.

Differences in their countries of origin, and also reason for migration, may explain the socio-economic differences between the two groups, with Sri Lankans having the highest scores regarding both education and participation in income-generating work. In Sri Lanka, the literacy level is about $90 \%$, with small gender differences ${ }^{(28)}$. In Pakistan, the literacy level is about $50 \%$, with a considerably lower proportion of literate women than men ${ }^{(28)}$. Sri Lankans came originally to Norway as refugees, whereas Pakistanis were work migrants. Later, many have come for family reunion from both groups ${ }^{(20)}$. The educational level in the sample is somewhat lower than in the Norwegian population $^{(20)}$ and the proportion in income-generating work is similar to that in the Norwegian population among men, but lower among women ${ }^{(27)}$.

We chose to use education and employment as indicators of socio-economic position. These two variables were differently associated with BMI, weight dissatisfaction and slimming attempts. They are commonly used indicators of socio-economic position. However, the use of these variables in migrant studies may pose some extra challenges, since their effect may be more complex across ethnic groups than in more homogeneous groups ${ }^{(21,29)}$. During migration, professional status enjoyed in the home country is often lost as education is not recognized by the host country. In the current study we chose to not classify occupational groups, only whether or not the person was employed in incomegenerating work. Employment will provide income and may give status, access to social contact with ethnic Norwegians, facilitate entry into the Norwegian society and development of language skills. This may happen in most working places. Another problem concerns the different educational systems across the countries. We included education from both the country of origin and Norway. This may have led to a higher risk of misclassification of educational level and given weaker associations than if the educational background had been more homogeneous.

\section{BMI/waist:bip ratio}

Mean BMI in our sample was considerably higher than that of South Asians in Pakistan ${ }^{(30,31)}$ and Sri Lanka ${ }^{(32,33)}$, 
as well as among the Norwegian population ${ }^{(34-36)}$. The tendency for a higher prevalence of central obesity in South Asians ${ }^{(21)}$ was taken into account by using WHR in addition to BMI, and by including the South-Asianspecific BMI cut-off for high disease risk ${ }^{(25)}$. About a quarter of the Sri Lankans and half of the Pakistanis were at high risk for developing chronic diseases.

BMI was inversely associated with education. This is in agreement with previous findings among non-Western immigrant groups in The Netherlands and the USA ${ }^{(37,38)}$. Lower socio-economic status is also related to BMI in the Norwegian population ${ }^{(39)}$.

BMI was inversely associated with the number of hot meals, which suggests that hot meals are exchanged with more energy-dense foods. Slimming attempts, being positively related to BMI, may include fewer hot meals and thereby explain some of the association between BMI and hot meals. The socio-economic, demographic and dietary variables explained only a small proportion of the differences in BMI in this group. Other factors, like social codes regarding food and eating, psychological distress as well as underlying genetic factors ${ }^{(40,41)}$, may be more powerful explanatory factors for these differences. WHR was to a larger extent than BMI associated with socioeconomic, demographic and dietary variables.

\section{Weight dissatisfaction and slimming attempts}

In agreement with findings from several ethnic groups ${ }^{(42-44)}$, women in Immigrant-HUBRO were more prone to be dissatisfied with their bodies than men, and while women wanted to lose weight, men more often wanted to gain weight. About one out of three normal-weight women were dissatisfied with their weight. Overestimation of one's own weight among under- and normal-weight women has been found in South Asia ${ }^{(45-47)}$. Bodily dissatisfaction may influence self-esteem in general and it may lead to unhealthy eating behaviour. The present study also revealed that many of those overweight and obese did not perceive that they weighed too much. This is in line with data from several other Western countries $^{(48,49)}$. A challenge in the prevention of lifestyle-related diseases is to raise awareness of weight-related problems without causing weight dissatisfaction among those of normal weight.

A study of ethnic Norwegian women showed that $80 \%$ of those overweight and $90 \%$ of those obese were slimming ${ }^{(35)}$. Among the Pakistani and Sri Lankan women, about $40 \%$ of the overweight and obese had been slimming the past year. Thus, the relationship between BMI and slimming attempts does not seem to be as strong among these two groups as among Norwegian women. Cachelin et al. suggest that the two cultures may have more or less the same body ideal, but the pressure to achieve it may vary ${ }^{(44)}$.

The women with higher education displayed more dissatisfaction with their weight, despite lower BMI, similar to findings among Western women ${ }^{(49,50)}$. Integration and length of stay in Norway had no significant associations with the women's weight dissatisfaction or with slimming. A thin ideal is not necessarily enough to affect degree of dissatisfaction or weight-related behaviour; the value must first be internalized ${ }^{(51)}$. Media exposure influences how people view themselves ${ }^{(52-54)}$, and so will those they spend time with, look up to and compare themselves with. Warren et al. suggest that ethnicity may protect women against bodily dissatisfaction in two ways: either because the group they belong to has ideals other than the ultra-thin Western ideal, or because they are valued for qualities other than external appearance ${ }^{(55)}$.

Our results show differences in how men and women attempt to diet. Women who were dissatisfied with their weight and/or attempted to slim had fewer daily meals, and those slimming also had breakfast less frequently. Most of the dissatisfied normal-weight men wanted to gain weight. Whether this is related to, or irrespective of, desired increased muscle size cannot be discerned from our data ${ }^{(17)}$. However, the inverse association between physical activity and weight dissatisfaction suggests that physical activity is more important than diet for attempts to achieve weight regulation among South Asian men.

\section{Conclusions}

The present study adds knowledge about some dietrelated and socio-economic factors associated with weight, weight dissatisfaction and slimming among immigrants in Oslo. Our results show that both bodily dissatisfaction and unrecognized overweight exist among South Asians in Norway. It is necessary to understand how different ethnic groups in the population think regarding body weight and slimming, in order to prevent or treat obesity as well as eating disorders ${ }^{(56)}$. More research is needed regarding factors influencing bodily dissatisfaction, the relationship between perception of weight and weight-change attempts, and how this affects the overall health situation among immigrants in Norway.

\section{Acknowledgements}

The data collection was conducted as part of the Oslo Immigrant Health Study carried out in 2002 as a collaboration between the Norwegian Institute of Public Health and the University of Oslo. No external funding was used, and no conflict of interest exists for any of the authors. All authors contributed in the conception and the writing of the article. Statistical analyses were executed by M.R.

\section{References}

1. World Health Organization/Food and Agriculture Organization of the United Nations (2003) Diet, Nutrition, and the Prevention of Chronic Diseases: Joint WHO/FAO Expert 
Consultation. WHO Technical Report Series no. 916. Geneva: WHO.

2. Abate N \& Chandalia M (2001) Ethnicity and type 2 diabetes: focus on Asian Indians. J Diabetes Complications 6, 320-327.

3. Anand SS, Yusuf S, Vuksan V et al. (2000) Differences in risk factors, atherosclerosis, and cardiovascular disease between ethnic groups in Canada: the Study of Health Assessment and Risk in Ethnic groups (SHARE). Lancet 356, 279-284.

4. Cappuccio FP, Cook DG, Atkinson RW et al. (1997) Prevalence, detection, and management of cardiovascular risk factors in different ethnic groups in south London. Heart 78, 555-563.

5. McNeely MJ \& Boyko EJ (2004) Type 2 diabetes prevalence in Asian Americans: results of a national health survey. Diabetes Care 27, 66-69.

6. Sevak L, McKeigue PM \& Marmot MG (1994) Relationship of hyperinsulinemia to dietary intake in south Asian and European men. Am J Clin Nutr 59, 1069-1074.

7. Goel MS, McCarthy EP, Phillips RS et al. (2004) Obesity among US immigrant subgroups by duration of residence. JAMA 292, 2860-2867.

8. Himmelgreen DA, Perez-Escamilla R, Martinez D et al. (2004) The longer you stay, the bigger you get: length of time and language use in the US are associated with obesity in Puerto Rican women. Am J Phys Anthropol 125, 90-96.

9. Kaplan MS, Huguet N, Newsom JT et al. (2004) The association between length of residence and obesity among Hispanic immigrants. Am J Prev Med 27, 323-326.

10. Neuhouser ML, Thompson B, Coronado GD et al. (2004) Higher fat intake and lower fruit and vegetables intakes are associated with greater acculturation among Mexicans living in Washington State. J Am Diet Assoc 104, 51-57.

11. Kelleher CC, Lynch JW, Daly L et al. (2006) The 'Americanisation' of migrants: evidence for the contribution of ethnicity, social deprivation, lifestyle and life-course processes to the mid-20th century coronary heart disease epidemic in the US. Soc Sci Med 63, 465-484.

12. Sobal J \& Stunkard AJ (1989) Socioeconomic status and obesity: a review of the literature. Psychol Bull 105, 260-275.

13. Nasser M (1988) Culture and weight consciousness. J Psychosom Res 32, 573-577.

14. Wildes JE, Emery RE \& Simons AD (2001) The roles of ethnicity and culture in the development of eating disturbance and body dissatisfaction: a meta-analytic review. Clin Psychol Rev 21, 521-551.

15. Ball K \& Kenardy J (2002) Body weight, body image, and eating behaviours: relationships with ethnicity and acculturation in a community sample of young Australian women. Eat Behav 3, 205-216.

16. Bush HM, Williams RG, Lean ME et al. (2001) Body image and weight consciousness among South Asian, Italian and general population women in Britain. Appetite 37, 207-215.

17. Ricciardelli LA, McCabe MP, Williams RJ et al. (2007) The role of ethnicity and culture in body image and disordered eating among males. Clin Psychol Rev 27, 582-606.

18. Bogers RP, Bemelmans WJ, Hoogenveen RT et al. (2007) Association of overweight with increased risk of coronary heart disease partly independent of blood pressure and cholesterol levels: a meta-analysis of 21 cohort studies including more than 300000 persons. Arch Intern Med 167, 1720-1728.

19. Hussain A, Claussen B, Ramachandran A et al. (2007) Prevention of type 2 diabetes: a review. Diabetes Res Clin Pract 76, 317-326.
20. Statistics Norway (2008) Innvandring og innvandrere (Immigration and immigrants). http://www.ssb.no/ innvandring/ (accessed March 2009).

21. Kumar BN, Meyer HE, Wandel M et al. (2006) Ethnic differences in obesity among immigrants from developing countries, in Oslo, Norway. Int J Obes (Lond) 30, 684-690.

22. Wandel M, Raberg M, Kumar B et al. (2007) Changes in food habits after migration among South Asians settled in Oslo: the effect of demographic, socio-economic and integration factors. Appetite 50, 376-385.

23. Mosdøl A (2004) Dietary assessment - the weakest link? A dissertation exploring the limitations to questionnaire based methods of dietary assessment. PhD Thesis, University of Oslo.

24. Natland ST, Wandel M \& Holmboe-Ottesen G (2004) Kosthold blant et utvalg av pakistanskfødte kvinner $i$ Oslo (Diet Among a Sample of Pakistani Born Women in Oslo). Oslo: University of Oslo.

25. World Health Organization (2004) Appropriate body-mass index for Asian populations and its implications for policy and intervention strategies. Lancet 363, 157-163.

26. Søgaard AJ, Selmer R, Bjertness E et al. (2004) The Oslo Health Study: the impact of self-selection in a large, population-based survey. Int J Equity Health 3, 3.

27. Statistics Norway (2008) Levekår blant innvandrere $i$ Norge 2005/2006 (Living Conditions Among Immigrants 2005/ 2006). Oslo: Statistics Norway.

28. The World Bank (2009) Country profile. http://go. worldbank.org/JVXVANWYYO (accessed April 2009).

29. Sundquist J \& Johansson SE (1998) The influence of socioeconomic status, ethnicity and lifestyle on body mass index in a longitudinal study. Int J Epidemiol 1, 57-63.

30. Jafar TH, Levey AS, White FM et al. (2004) Ethnic differences and determinants of diabetes and central obesity among South Asians of Pakistan. Diabet Med 21, 716-723.

31. Jafar TH, Qadri Z \& Chaturvedi N (2008) Coronary artery disease epidemic in Pakistan - more electrocardiographic evidence of ischemia in women than in men. Heart $\mathbf{9 4}$, 408-413.

32. Tennakoon TMS (2006) Cardiovascular risk factors in urban Tamils in Central Province of Sri Lanka: a community based study. Master's Thesis, University of Oslo.

33. Wijewardene K, Mohideen MR, Mendis S et al. (2005) Prevalence of hypertension, diabetes and obesity: baseline findings of a population based survey in four provinces in Sri Lanka. Ceylon Med J 50, 62-70.

34. Meyer HE \& Tverdal A (2005) Development of body weight in the Norwegian population. Prostaglandins Leukot Essent Fatty Acids 73, 3-7.

35. Hjartaker A, Laake P \& Lund E (2001) Body mass index and weight change attempts among adult women. The Norwegian Women and Cancer Study. Eur J Public Health 11, 141-146.

36. Reas DL, Nygard JF, Svensson E et al. (2007) Changes in body mass index by age, gender, and socio-economic status among a cohort of Norwegian men and women (1990-2001). BMC Public Health 7, 269.

37. Cornelisse-Vermaat JR \& van den Brink HM (2007) Ethnic differences in lifestyle and overweight in the Netherlands. Obesity (Silver Spring) 15, 483-493.

38. Yeh MC, Fahs M, Shelley D et al. (2009) Body weight and length of residence in the US among Chinese Americans. $J$ Immigr Minor Health 11, 422-427.

39. Norwegian Institute of Public Health (2007) Sosial ulikhet $i$ belse: en faktarapport (Social Inequalities in Health; A Fact Report), 1st ed. Oslo: Norwegian Institute of Public Health.

40. O'Dea K (1995) Overview over the thrifty genotype hypothesis. Asia Pac J Clin Nutr 4, 339-340. 
41. Barker D (1997) Prenatal influences on disease later in life. In Diet, Nutrition and Chronic Disease: Lessons from Contrasting Worlds, pp. 41-54 [K McPherson and SS Prakash, editors]. Chichester: Wiley.

42. Smith DE, Thompson JK, Raczynski JM et al. (1999) Body image among men and women in a biracial cohort: the CARDIA Study. Int J Eat Disord 25, 71-82.

43. Demarest J \& Allen R (2000) Body image: gender, ethnic, and age differences. $J$ Soc Psychol 140, 465-472.

44. Cachelin FM, Rebeck RM, Chung GH et al. (2002) Does ethnicity influence body-size preference? A comparison of body image and body size. Obes Res 10, 158-166.

45. Suhail K \& Zaib-u-Nisa (2002) Prevalence of eating disorders in Pakistan: relationship with depression and body shape. Eat Weight Disord 7, 131-138.

46. Gupta MA, Chaturvedi SK, Chandarana PC et al. (2001) Weight-related body image concerns among 18-24-yearold women in Canada and India: an empirical comparative study. J Psychosom Res 50, 193-198.

47. Sinhababu A (2007) A study on weight status and weight perception of GNM students of a nursing training centre, Bankura, West Bengal. J Indian Med Assoc 105, 85-87.

48. Crawford D \& Campbell K (1999) Lay definitions of ideal weight and overweight. Int J Obes Relat Metab Disord 23, 738-745.

49. Wardle J \& Johnson F (2002) Weight and dieting: examining levels of weight concern in British adults. Int J Obes Relat Metab Disord 26, 1144-1149.
50. McLaren L \& Kuh D (2004) Women's body dissatisfaction, social class, and social mobility. Soc Sci Med 58, $1575-1584$.

51. Fingeret MC \& Gleaves DH (2004) Sociocultural, feminist, and psychological influences on women's body satisfaction: a structural modelling analysis. Psychol Women $Q \mathbf{2 8}$, 370-380.

52. Hatoum IJ \& Belle D (2004) Mags and abs: media consumption and bodily concerns in men. Sex Roles $\mathbf{5 1}$, 397-407.

53. Groesz LM, Levine MP \& Murnen SK (2002) The effect of experimental presentation of thin media images on body satisfaction: a meta-analytic review. Int J Eat Disord 31, $1-16$.

54. Cahill S \& Mussap AJ (2007) Emotional reactions following exposure to idealized bodies predict unhealthy body change attitudes and behaviours in women and men. J Psychosom Res 62, 631-639.

55. Warren CS, Gleaves DH, Cepeda-Benito A et al. (2005) Ethnicity as a protective factor against internalization of a thin ideal and body dissatisfaction. Int J Eat Disord 37, 241-249.

56. Thompson JK (1996) Body image, eating disorders, and obesity - an emerging synthesis. In Body Image, Eating Disorders, and Obesity: An Integrative Guide for Assessment and Treatment, pp. 1-20 [JK Thompson, editor]. Washington, DC: American Psychological Association. 